\title{
A subversão da História pela Literatura: Considerações sobre O Noivado em São Domingos de Heinrich von Kleist*
}

\section{Ulrich Johannes Beil ${ }^{* *}$}

\begin{abstract}
Unlike cultural studies and their tendency to read literary texts as epistemological discourses, the target of this study is to develop the potential of difference between fictional and non-fictional texts, in view of Heinrich von Kleist's novella Die Verlobung in St. Domingo. In this perspective, not only does Kleist's text use colonialist, racist, historiographic discourses, but also explicitly deals with them from the very beginning. Colonialist dualism and individual encounter, racist stereotypes and narrative contingency, historiographic discourse and unexpected event are connected in a paradoxical manner. Although the discourse effects seem to prevail, the literary text asserts itself in the process of narration by undermining and challenging the power of the discourses.
\end{abstract}

Keywords: Heinrich von Kleist; Haiti; Colonialism; Racism; Historiography.

Zusammenfassung: Im Unterschied zu kulturwissenschaftlichem Vorgehen, das dazu tendiert, literarische Texte genauso $\mathrm{zu}$ lesen und $\mathrm{zu}$ benutzen wie epistemologische Diskurse, zielt der vorliegende Artikel darauf ab, in Kleists Novelle Die Verlobung in St. Domingo eben jenes Potential aufzuspüren, mit dem sich der fiktionale vom nichtfiktionalen Text unterscheidet. So gesehen, verwendet der Text Kleists die kolonialistischen, rassistischen, historiographischen Diskurse der Zeit um 1800 nicht nur, sondern setzt sich von Anfang an dezidiert mit ihnen auseinander. Kolonialistischer Dualismus und individuelle Begegnung, rassistische Stereotypen und narrative Kontingenz, historiographischer Diskurs und unerwartetes Ereignis gehen eine paradoxe Verbindung ein. Zwar scheinen die Diskurseffekte über weite Strecken zu dominieren; im Prozess der Narration aber behauptet sich letztlich der literarische Text, indem er die Macht der Diskurse immer von neuem unterminiert und in Frage stellt.

Stichwörter: Heinrich von Kleist; Haiti; Kolonialismus; Rassismus; Historiographie.

Palavras-chave: Heinrich von Kleist; Haiti; Colonialismo; Racismo; Historiografia.

\footnotetext{
* O autor é pesquisador na Universidade de Zurique e docente na Universidade de Munique. Entre 2000 e 2004 trabalhou como Professor Visitante junto à Área de Alemão, na FFLCH/USP.

** Uma primeira versão desse texto foi apresentada na Semana de Literatura Alemã em setembro 2004 na FFLCH/USP. Agradeço a Fátima Vasco pela excelente tradução dos parágrafos centrais para o português do Brasil.
} 


\section{Beil, U. J. - A subversão da História pela Literatura: O Noivado em São Domingos}

Será que a Literatura tem poder para se 'infiltrar' no processo histórico, do qual ela própria também faz parte? Será que a ficção consegue protestar contra 'fatos', para reivindicar seus direitos em relação a eles? Trocando em miúdos: não se trata da História em si - seja lá qual for a definição que se tenha dela - mas de um discurso, o discurso historiográfico que, enquanto linguagem especial, pode juntar-se a ou concorrer com aquela outra linguagem a que chamamos de Literatura. Todo leitor de Heinrich von Kleist sabe que em seus dramas, e especialmente também em suas novelas, ele trabalha com discursos historiográficos. Sabemos do valor que Kleist deu à indicação de datas e localidades, à fidedignidade histórica em suas narrativas, por exemplo, quando o título Michael Kohlhaas ganha o subtítulo "De uma crônica antiga" (Aus einer alten Chronik), ou quando ele afirma contar A Marquesa d'O... (Die Marquise von O... ) "A partir de um acontecimento real" ("Nach einer wahren Begebenheit”). Esse interesse em uma base histórica combina também com a inclinação de Kleist em construir anedotas ou de desenvolver narrativas a partir de anedotas. $\mathrm{Na}$ anedota, que o historiador Joel Fineman descreveu como "the literary form that uniquely lets history bappen", entram em contato o discurso historiográfico e o 'paradiscurso' da Literatura, a grande e a pequena história, petite histoire e grand récit.

Seria a subversão do discurso historiográfico pela Literatura? À primeira vista, o oposto parece ser verdadeiro: é como se Kleist estivesse interessado em inserir sua prosa num contexto histórico, em legitimar seu trabalho ficcional dando-lhe uma base factual. Num primeiro momento, temse a impressão de uma mimese do estilo historiográfico: a linguagem é detalhada, de certa forma, hiper-exposta (super-iluminada), repleta de orações subordinadas e apostos, às vezes até burocraticamente rebuscada, e lembra a linguagem de Kafka. ${ }^{2}$ No tocante à subversão, entretanto, a minha tese é a de que a linguagem onipresente dos discursos esclarecidos - principalmente os da historiografia, mas também, em parte, da filosofia, da teologia, do direito ou das ciências naturais - é operacionalizada em Kleist até o ponto em que seus mecanismos e modelos de esclarecimento não funcionam mais. $\mathrm{O}$ potencial subversivo da prosa de Kleist é percebido, entre outros fatores, por

\footnotetext{
1 "The anecdote is the literary form that uniquely lets history happen by virtue of the way introduces an opening into the teleological, and therefore timeless, narration of beginning, middle, and end." (FINEMAN 1989: 49sq.).

2 Sobre o estílo de Kleist cf. CASTRO 2006: 38-54; cf. também Rosenfeld 1993: 84: O estilo de Kleist é "complexo, enovelado, cheio de orações subordinadas, criando tensões e dando ao ritmo da frase estilhaçada um caráter ofegante e furioso". Cf. NEUMANN 2003: 190: “Unter dem Aspekt narrativer Strategien gesehen, simuliert Kleists dominikanische Novelle [...] den Prozess der Historiographie selbst - und zwar als Zusammenspiel zwischen kontingenten Ereignissen und prägnanten Orientierungsmustern, die, wie die historischen 'Anekdoten', zum Verständnis, zur Modellierung, zur Präformierung von Wabrnehmung aufgerufen werden, ja zur Stiftung von Weltverständnis fübren können."
} 


\section{Beil, U. J. - A subversão da História pela Literatura: O Noivado em São Domingos}

meio da incongruência entre uma tese geral e um exemplo característico, conforme apresenta Paul de Man em seu ensaio sobre Sobre o Teatro de Marionetes (Über das Marionettentheater) (DE MAN 1979; BEIL 2006). Pode-se dizer que há sempre uma série incalculável de exemplos que vão contra a teoria e acabam por anular a sua suposta plausibilidade: uma experiência que todo professor entende facilmente. A minha suposição é que essa incongruência também pode ser observada nas narrativas, ou seja, que o narrador, em seu esforço de esclarecer a sua posição discursiva, por meio de seus exemplos se coloque em uma situação que justamente acabe por evidenciar os limites, as contradições e os abismos dessa posição. Desse modo, os pólos da ordem binária do discurso - bom-mau, verdadeiro-falso, preto-branco cruzam-se concretamente de tal forma, que não mais será possível diferenciálos (situação de indiferença). Analogamente, perspectivas que desfrutam de um local fixo e definido dentro do discurso poderiam entrar em conflito, de modo que nenhuma posição 'verdadeira' pareça ser possível. É exatamente aí que começa a 'literatura' - e aí cabe descobrir o que caracteriza a 'literatura' em relação ao 'discurso'. De qualquer forma, não se trata de algo que estaria próximo do contexto do Romantismo Alemão: de um além-mundo poético, seja ele qual for, em relação a este mundo objetivamente calculável. A observação de Goethe de que "em seu apogeu, a poesia aparece completamente objetiva” („auf ibrem böchsten Gipfel scheint die Poesie ganz. äußerlich") (GOETHE 1907: Nr. 510; REUSS 2003: 81) talvez não possa ser aplicada a nenhum outro autor alemão tão bem quanto a Heinrich von Kleist.

A fim de esclarecer o que acabo de dizer, apresento agora um exemplo, na esperança de que a minha hipótese não crie dificuldades. Trata-se da novela O Noivado em São Domingos (Die Verlobung in St. Domingo). Este texto publicado poucos meses antes do suicídio de Kleist no ano de 1811 (no segundo volume das Erzählungen), e sendo, assim, uma espécie de testamento literário - é uma das obras mais discutidas desse autor, e justamente nos últimos dez, quinze anos surgiram estudos bastante significativos, que não podem ser ignorados. Nesses textos, retomam-se, sob novas perspectivas, as questões: se o narrador - entendido aqui como o próprio autor Kleist assume ou não uma posição colonialista-racista, e se a narrativa, ao ser lida contra a posição do narrador, possa livrar o autor Kleist dessas acusações (sobre a posição precária do narrador cf. HORN 1978 e FISCHER 1988)³. Se, por um

\footnotetext{
${ }^{3} \mathrm{Na}$ minha argumentação, não se trata de desculpar o autor Heinrich von Kleist. A caracterização do "seu" racismo mereceria um outro ensaio. Cf. SCHMIDT 2003: 247: "In die Berliner Abendblätter nahm Kleist einen Bericht Über den Zustand der Schwarzen in Amerika auf [...], der aus der Feder des ultrakonservativen Autors Louis de Sevelinges im Mercure de France im Dezember 1810 erschienen war und die Sklavenhaltung in English Guayana
} 
lado, durante os anos 70 e no início da década de 80, Kleist era visto como um irônico hábil, que apenas citava o racismo de seus contemporâneos, expunhao conscientemente, mas rompia com ele artisticamente (HERRMANN 1998: 114), desde a década de 90 , em sintonia com a discussão acerca do póscolonialismo, vê-se um viés de racismo nessa novela. O que se pode observar nessas análises é uma tendência de se relacionar o texto como um todo a uma posição discursiva do narrador, ainda que aqui e ali se reconheçam pequenos desvios nessa linha. Assim, ou o narrador é reduzido a essa tendência ou abandonam-se oposições e paradoxos que remetem a uma crise geral do discurso colonialista. E, nesse sentido, aparece em um artigo de Hansjörg Bay: "o narrador de Kleist não escapa do fato de que a ordem das coisas por ele próprio idolatrada não está mais intacta” (BAY 1998: 105).

Deixando de lado essa tendência, procura-se, a seguir, mostrar as qualidades especificamente literárias da prosa de Kleist - aquilo que nos desperta "o prazer do texto" no sentido de Roland Barthes. Por um lado, essas qualidades surgem sob a égide do discurso, como um tipo de discurso mimético (Diskurs-Mimikry); por outro, porém, ao serem eficazes, elas também questionam os esquemas desse discurso. Os esforços filológicos em relação aos textos literários têm o fardo tácito de trazê-los de volta para a linguagem coerente de um discurso por meio da hermenêutica, do estruturalismo ou da teoria sistêmica, em vez de neles ressaltar o que se opõe à integração ao Logos como era o caso em relação ao Mito. Sendo assim, é necessário devolver ao texto a sua differentia specifica, a sua presença literária, ou seja, o que o difere de textos que se entendam como re-presentação de uma teoria.

Não é preciso nenhum grande esforço hermenêutico para ver que o discurso historiográfico no trecho inicial do Noivado em São Domingos está presente em cada uma de suas linhas. Leiamos a primeira frase: "Em Port au Prince, do lado francês da Ilha de São Domingo, no início deste século, quando os negros matavam os brancos, vivia um terrível velho preto, cujo nome era Congo Hoango". "Somos imediatamente remetidos à época das lutas pela libertação dos escravos afro-americanos no lado francês do Haiti,

schönfärberisch darstellt." Cf. CASTRO 2006: 114: "Este texto, por sua vez, reproduz trechos do livro $A$ Voyage to Demeray, containing a statistical account of the settlements there, and of those of the Essequebo, the Berboice and other contigous rivers of Guayana, de Henry Bolingbroke, publicado no mesmo ano. O texto defende que os negros escravos, não obstante o fato de terem sido transformados em mercadorias, receberiam um tratamento humanitário [...].” Cf. também Angress 1977; GILMAN 1975; FiCK 2004.

4 KLEIST 1990: 699: „Zu Port au Prince, auf dem französischen Anteil der Insel St. Domingo, lebte, zu Anfange dieses Jahrbunderts, als die Schwarzen die Weißen ermordeten, ein fürchterlicher alter Neger, namens Congo Hoango ". Os citações de Kleist são traduzidos por Fátima Vascon. Para a leitura do texto inteiro em Português recomendo a tradução da Claudia Cavalcanti (KLEIST 1992). 
que aconteceram entre 1791 e 1803, em um período que marca uma profunda quebra na história colonial: "Trata-se do fim daquela que na época foi a mais rica das colônias no novo mundo e da primeira luta de libertação bem sucedida de um grupo populacional não branco contra os senhores coloniais europeus".5 Ao mesmo tempo, o narrador não deixa dúvidas em relação à posição por ele representada no discurso - ou seja, uma posição afirmativa em conformidade com seu tempo. A relação infrator-vítima está claramente elaborada e ainda é ilustrada com exatidão, à medida que o "preto" Hoango é caracterizado como rebelde, ingrato e cruel, que "no meio do delírio geral da vingança, que se propagava nestas plantações por causa dos passos imprudentes do convento nacional, foi um dos primeiros a [...] meter na cabeça do seu senhor uma bala", 6 matou sua família, acabou com a plantação e "em sua desumana sede de vingança" obrigou a amante Babekan e sua filha bastarda Toni a recolher, como disfarce, brancos fugitivos em sua casa, para, por fim, matá-los (KLEIST 1990: 699 s.).

Após essa introdução, se o propósito fosse resumir a trama do conto em si, de acordo com a perspectiva colonial-racista do narrador - e isso é o que faz a maioria das interpretações do Noivado - então, o resumo ficaria mais ou menos assim: Certa noite, um oficial suíço fugitivo, Gustav von der Ried, cuja família por medo dos rebeldes negros se mantém escondida na selva, foi à casa de Congo Hoango em busca de ajuda e abrigo. Lá, ele encontra Babekan e Toni, que, por meio de acalentadores argumentos como também pela cor de suas peles mulata e mestiça respectivamente, tentam convencê-lo de que elas próprias estariam sob a ameaça do agora ausente Hoango, devido à simpatia deste pelos brancos. Durante essa longa conversa, Gustav vai adquirindo mais e mais confiança nas duas, e, entre outras coisas, fica sabendo que Toni, de quinze anos, é filha de um comerciante de Marselha. Em seguida, as mulheres o alojam em um quarto, e nele, enquanto Toni se prepara para lavar os pés de Gustav, os dois se aproximam. Gustav gosta da menina e, depois que ele lhe conta da semelhança dela com sua ex-namorada Mariane Congreve, os dois afirmam seu amor e dormem juntos. Na manhã seguinte, Babekan apresenta um plano a sua filha, de como poderiam entregar toda a família do suíço, e ele próprio já confinado, à violência de Congo Hoango. Toni se opõe ao plano em um primeiro momento, enfatiza a inocência de

${ }^{5}$ BAY 1989: 80:, Es handelt sich um das Ende der damals reichsten Kolonie in der neuen Welt und um den ersten erfolgreichen Befreiungskampf einer nicht-weißen Bevölkerungsgruppe gegen die europäischen Kolonialherren ". Sobre o contexto histórico cf. entre outros: BUCH 1976; BLACKBURN 1988; JAMES 1989; ZANTOP 1994; GRIBNITZ 2002.

${ }^{6}$ KLEIST 1990: 699: „Congo Hoango war [...] bei dem allgemeinen Taumel der Rache, der auf die unbesonnenen Schritte des Nationalkonvents in diesen Pflanzungen aufloderte, einer der Ersten, der die Büchse ergriff, und, eingedenk der Tyrannei, die ihn seinem Vaterlande entrissen hatte, seinem Herrn die Kugel durch den Kopfjagte." 
Gustav, acaba, porém, cedendo pro forma para não se indispor com a mãe e não prejudicar o seu amado. Aí se inicia o que já foi chamado de "carreira racista" ("Rassenkarriere") de Toni (BAY 1998: 93). Gustav tinha contado a Toni duas anedotas: uma sobre uma negra traidora, que prende seu ex-amo na cama para infectá-lo com febre amarela, e outra sobre a branca quase santa Mariane, que morreu por seu amado. A partir da cena com a mãe, Toni transforma-se, passo a passo, como em um tipo de romance de formação condensado, indo de um modelo de feminilidade para outro (BAY 1998: 94; WEIGEL 1991), ou seja, transforma-se de ajudante traidora de Congo Hoango a uma "bela alma" ("schöne Seele"), tal como aparece no fim. Nessa noite de amor, depois de ganhar de Gustav a cruz de ouro de Mariane de presente de noivado (KLEIST 1990: 710), passa a assumir, sucessivamente, valores ocidentais, cristãos, e ajoelha-se, na noite seguinte, frente à "imagem da Virgem Maria” (KLEIST 1990: 716), antes de dirigir-se ao amado adormecido no andar de cima. E agora vem a cena mais precária, mais trágica da novela: exatamente nesse momento, Congo Hoango volta antes do esperado, e Toni, para driblar a desconfiança de sua mãe, amarra Gustav em sua cama (KLEIST 1990: 718). Age assim para salvar a vida dele, ganhar tempo, buscar a família suíça escondida na selva e, com os brancos, dominar Congo Hoango e seus homens. O plano funciona: Toni consegue colocar a família a salvo na casagrande e também dominar Congo Hoango e Babekan. Gustav, porém, acha que foi traído por ela. No momento em que tudo parece acabar bem, ele a mata com sua arma e, quando a família lhe explica o engano que cometeu, desesperado, ele se suicida (KLEIST 1990: 723-725).

As interpretações da história de Kleist como um texto quase discursivo chegam a conclusões como esta: "explicitamente, é possível que algo de negativo tenha sido dito sobre os brancos [...], implicitamente, porém, na construção dos sistemas de imagens e valores, a narrativa se dá de uma perspectiva branca, colonialista [...]" (GREINER 2000: 431; cf. também SCHMIDT 2003: 244-256). De fato, há, no texto, indícios suficientes para manter-se esse programa de discurso, por exemplo, quando, apesar de seu encantamento pela beleza de Toni, Gustav nota a cor de sua pele como “repulsiva” (,anstößig") (KLEIST 1990: 708). Porém, nesse tipo de interpretação e em interpretações semelhantes, somente a mimese do discurso (DiskursMimikry) é fortalecida e levada a sério; não se olha para o fato de que o texto desenvolva o seu real peso literário e fascinação exatamente no contrafluxo do modelo discursivo. Isto é, não se trata somente de levantar as contradições e os disparates no sentido de uma desconstrução do discurso colonialista, mas 


\section{Beil, U. J. - A subversão da História pela Literatura: O Noivado em São Domingos}

de salientar as práticas literárias positivas, que, aparentemente, ao seguir o discurso como exemplo de tese da história, suspendem a validade de seu esquema. ${ }^{7}$ Trata-se de um momento lingüístico, ou, pelo menos, não apenas lingüístico, de um momento definido por seu conteúdo.

Hoje há excelentes análises da estrutura da narrativa, dos motivos e da intertextualidade desse conto, como, por exemplo, as de Gerhard Neumann, Sigrid Weigel, Hans Peter Herrmann, Hansjörg Bay, Elke Heckner, Barbara Gribnitz e Herbert Uerlings, apenas para citar alguns deles (NEUMANN 2003; Gribnitz 2002; Neumann 2001; HECKNER 2001; Herrmann 1998; BAy 1998; WeIGEL 1991; UERLINGS 1991). Logo no início, foi-nos esclarecido o papel fundamental da percepção, em que a linguagem discursiva se separa da linguagem narrativa. Trata-se exatamente de uma data histórica, 1803, quando o general negro Dessalines, com 30.000 militares, avança contra Port au Prince, e aí já começa a história em si: "E assim aconteceu que [...] na escuridão de uma noite tempestuosa e turbulenta, alguém bateu à porta do fundo da casa [do preto Congo Hoango]". ${ }^{8}$ A cena de iniciação (KLEIST 1990: 700), na qual o estrangeiro, Gustav, estende sua mão "para pegar a mão de Babekan" ("um die Hand Babekans zu ergreifen") e certificar-se da identidade dela - pró ou contra o branco -, permite a leitura de um teatro da percepção ou de um "teatro do reconhecimento" ("Erkundungstheater": NEUMANN 2001: 101; cf. SCHERPE 1998; cf. HAVERKAMP 1995), que se caracteriza pelo acaso e pela surpresa. Logo no início já fica claro, que a história em si está longe de ser um porto seguro, que o modelo discursivo do reconhecimento de amigo e de inimigo em uma "noite" escura depende de sinais físicos e emocionais, que são difíceis de interpretar. A encenação de cor e luz assumiu um papel especialmente importante em quase todas as análises. Observou-se repetidas vezes, que "na história de Kleist a pele 'branca' e especialmente a cor do rosto, concentra-se no campo semântico de luz/sol/dia/Europa, e a negra concentra-se no campo semântico de escuridão/sombra/noite/África [...]".? $\mathrm{Na}$ maior parte das vezes, essas verificações foram apresentadas como concretização narrativa do esquema colonialista preto-branco. É verdade que a "mestiça" ("Mestize") Toni ${ }^{10}$, mescla em diversos momentos essa estrutura

\footnotetext{
${ }^{7}$ Cf. também HeRRMANN 1998: 128: "Kleist installiert die Diskurse, indem er sie bricht."

${ }^{8}$ KLEIST 1990: 700:,Demnach traf es sich, daß [...] in der Finsternis einer stürmischen und regnigten Nacht, jemand an die bintere Tür seines [des Negers Congo Hoangos] Hauses klopfte". O "demnach" marca a virada entre a linguagem da Historiografia e a linguagem da narração.

9 BAY 1998: 91: [...dass] „in Kleists Erzählung die ,weiße' Haut- und insbesondere Gesichtsfarbe im Wortfeld Licht/Sonne/Tag/Europa, die ,schwarze" im Wortfeld Finsternis/Schatten/Nacht/Afrika [...] angesiedelt wird. "Cf. HAVERKAMP 1995.

10 Cf. GRIBNITZ 2002: 81: "Tonis Kennzeichnung als Mestize und durch den Vornamen produziert auch geschlechtliche Uneindeutigkeit. Zum einen reigt die Bezeichnung 'Mestize' die grammatisch männliche Endung [...]. Zum anderen trägt Toni
} 


\section{Beil, U. J. - A subversão da História pela Literatura: O Noivado em São Domingos}

dual, mas, no geral, as análises contentam-se com o fato de que a "entrada de uma pessoa de cor no mundo dos brancos" seja aqui apresentada como "ascensão" e que Toni, dessa forma, seja totalmente "apanhada pelo dualismo da construção de raças” (HERRMANN 1998: 131; BAY 1998: 100).

Se estivermos prontos para levar os elementos narrativos mais a sério do que a estrutura discursiva, será necessário ver Toni como a incorporação do distúrbio desse código binário, como aquele tertium, que sempre volta a abalar a estabilidade do discurso colonialista. No processo da narrativa sobrepõem-se momentos que expressam a posição intermediária entre o mundo dos negros e o mundo dos brancos. Sigrid Weigel deixa claro: "nem negra nem branca, a pele amarelada [de Toni] é sinal de uma ambivalência, ou melhor, de um desconhecimento em relação à identidade da menina. O 'amarelo' da pele de Toni une-se, de um lado, ao Sol da Europa, e de outro, à febre amarela dos negros doentes; tenciona as possibilidades de interpretar a cor de sua pele entre o conceito de mulher branca e pura e a imagem do corpo negro e contagioso."11 As ambivalências ficam ainda mais claras, quando se observa a linguagem da mulata Babekan e da mestiça Toni. A comparação étnica de Babekan com um "corpo", cujos membros, por não serem idênticos, se "enfurecem" ("wüten") uns com os outros, ${ }^{12}$ conforme Elke Heckner mostrou, permite uma interpretação a partir do conceito de mimese colonial (Mimikry) de Homi Bhabha, como adaptação de metáforas colonialistas com intenção parodística (HECKNER 2001: 233-236; cf. BHABHA 1994). Aqui também entram os paradoxos do diálogo da cena do noivado, para a qual $\mathrm{H}$. Uerlings recentemente chamou a atenção (UERLINGS 1997: 34). Mas concentremo-nos agora em Toni.

Conforme a história se desenvolve, praticamente a cada página, encontram-se elementos que confundem e trazem insegurança à posição fixa de discurso - apesar de seu dualismo permanecer, o tempo todo, como pano de fundo. Essa situação fica clara nos dois últimos exemplos: a cena da lavagem dos pés e a cena das amarras. Normalmente, na literatura, a cena da

einen geschlechtlich doppelt markierten Namen, der als Abkürzung sowobl für Antonia/ Antonie als auch für Anton/ Antonio gilt."

11 WEIGEL 1991: 216: „Weder schwarz noch weiß, ist die [Tonis] gelbliche Hautfarbe Zeichen einer Ambivalenz bzw. eines Nicht-Wissens über die Identität des Mädchens. Das ,Gelb'von Tonis Haut verbindet sich dabei einerseits mit der ,Sonne Europas' und andererseits mit dem Gelbfieber der kranken Schwarzen; es spannt die Möglichkeiten, ibre Hautfarbe zu deuten, zwischen dem Konzept der reinen, weißen Frau und der Vorstellung vom ansteckenden, schwarzen Körper auf. "Cf. HERRMANN 1998: 127: "So endet Tonis vermeintliche Selbstverwirklichung [...] im Niemandsland zwischen den Rassen." Cf. GRIBNITZ 2002: 95: "So changieren Tonis Positionierungen im Koordinatensystem mit den Fixpunkten schwarz-weiß und weiblich-männlich, obne einen festen und eindeutigen Platz. zu erreichen, nicht einmal im Tod."

12 KLEIST 1990: 703: "IJa, diese rasende Erbitterung', beuchelte die Alte. 'Ist es nicht, als ob die Hände eines Körpers, oder die Zähne eines Mundes gegeneinander wüten wollten, weil das eine Glied nicht geschaffen ist, wie das andere?" 
lavagem dos pés é analisada - quando é levada em consideração - como um tipo de iniciação de Toni ao modelo de comportamento ocidental cristão; a cena das amarras, no geral, é vista como um momento de grande e trágico mal-entendido - erro de interpretação da ação por parte de Gustav. Num exame mais acurado, observa-se que, se, por um lado, em ambas as cenas funciona o mecanismo discursivo comum, por outro, esse mecanismo se enfraquece profundamente, causando a anulação de seu efeito. Com os motos comuns de polissemia e indecisão ainda não se chega ao cerne da questão. Trata-se de perceber que, à primeira vista, o significado mais evidente (negro) cruza-se com seu oposto (branco) e, dessa forma, desenvolve-se um tertium vago, suspenso, uma não-localidade, que não é marcada por ninguém, tal como a mestiça Toni. Assim, a lavagem dos pés pode ser interpretada, em uma primeira leitura, como parte daquele programa assassino em relação aos brancos, planejado na casa de Congo Hoango, um serviço quase erótico, uma medida para angariar confiança. Uma segunda leitura teria como referência o evidente contexto bíblico, a lavagem dos pés de Cristo pela pecadora arrependida Maria Madalena, registrado por Lucas 7,4 (cf. também NEUMANN 2003: 186-187). Uma mesma passagem pode tanto ser lida como parte do programa "negro", como parte do programa "branco"; porém, levando-se em consideração o fato de que a lavagem em si nem ocorreu (só os "preparativos", nur "die Vorkehrungen": KLEIST 1990: 708), para além das relações discursivas, essa cena torna-se pano de fundo do jogo do amor, que a partir de então se inicia. Oato de amor é marcado no texto pela ausência de uma letra e a inclusão de um sinal fálico de apóstrofe, ${ }^{13}$ é o ápice, não apenas de um desejo proibido, mas também de uma mistura escandalosa entre os pólos "preto" e "branco" do discurso colonial.

Um tertium erótico comparável desenvolve-se em uma leitura mais precisa da cena das amarras. Embora ela se apresente como trágico momento de transição de todo o conto, tal cena ficou estranhamente esquecida na literatura. No entanto, ela corresponde à cena da lavagem dos pés sob vários aspectos: tanto aqui como lá, a pura facticidade das atitudes de Toni remetem a um significado "negro", que preenche as expectativas de Congo Hoango em relação à solidariedade da menina. (Em tempo: Para Gustav a cena das amarras guarda até o final, o trágico desfecho, esse significado negro, razão pela qual ele se torna uma espécie de quadro enigmático do narrador, como alguém que, após um curto episódio erótico, identifica a 'meio-negra'

13 Isso se pode observar só no texto alemão, especialmente na Brandenburger Kleist-Ausgabe: KLEIST 1988: 43: "W as weiter erfolgte, brauchen wir nicht zu melden, weil es jeder, der an diese Stelle kommt, von selber lies't'. Cf. também REUß 2003: 74-75. 
totalmente com o pólo 'negro' do programa colonialista; ele não consegue acreditar no exercício de equilíbrio híbrido dessa moça.) Como essa cena é introduzida por uma reflexão narrativa a favor de Toni ("se ele a tivesse encontrado em sua cama nesse momento, Gustav não a teria julgado traidora, e [...] ido parar sem pensar nos braços do negro Hoango?”), ${ }^{14}$ o leitor está seguro das boas e 'brancas' intenções da moça; entende perfeitamente que ela seja tomada por um "medo impronunciável" e opte pela arriscada 'solução' das amarras. Quando Congo Hoango volta de repente e vê a moça sair sorrateiramente do quarto de Gustav, ele a chama de "desleal" e de "traidora" ("Er rief: 'die Treulose! Die Bundbrüchige!": KLEIST 1990: 718). Acuada, ela defende-se com palavras indignadas: "o estrangeiro está aí deitado, amarrado por mim em sua cama; e, por Deus, essa não foi a pior coisa que eu já fiz na minha vida!" ${ }^{15}$ Nesta frase, observa-se não apenas uma ligação intertextual com Os Bandoleiros (Die Räuber) de Schiller (no qual Schweizer, depois de ter matado Spiegelberg, formula uma frase parecida), como também, a partir da perspectiva do leitor, a ambivalência existente no próprio conceito de amarra: a frase pode relacionar-se tanto ao princípio de vingança de Congo Hoango como ao sentimento de justiça recentemente despertado em Toni a favor dos perseguidos brancos (LUBKOLL 2001: 132). Nesse sentido, merece atenção especial a apresentação estilística da ação. Por meio da descrição do ato de amarrar, os leitores também se envolvem nessa ação, por reconhecer ambigüidade muito freqüente em Kleist - que a corda jogada nas mãos de Toni é uma forma de subjugar e, ao mesmo tempo, de ligar os amantes de forma indissolúvel; lê-se no texto: "ela abraçou o jovem" (,Sie umschlang den Jüngling"), ... "enlaçando com vários nós a mãos e pés [...]" (,vielfache Knoten schüržend, an Händen und Füßen damit [...]": KLEIST 1990: 718). Reconhecemos aí que a corda faz um nó ao emaranhar a opção negra com a branca, uma à outra, de forma que exatamente os termos "abraço" e "enlaçamento" („Umscblingen" und "Schüržen") criem uma presença, um tertium estéticoerótico, que vai muito além da área de validação do discurso colonialista. É como se essa corda, esse tecido, que tanto pode salvar como estrangular, fosse também, acima de tudo, um símbolo do próprio texto, que nas entrelinhas diz algo a mais do que aquilo que ele pretende dizer, e nos deixa seus nós para serem elaborados, sem que tenhamos, como Alexandre o Grande em Górdio, uma espada apropriada à disposição.

\footnotetext{
14 KLEIST 1990: 718: [Würde Gustav nicht,] ,wenn er sie in dieser Stunde bei seinem Bette fände, für eine Verräterin halten, und [...] dem Neger Hoango völlig besinnungslos in die Arme laufen"?

15 KLEIST 1990: 718: „[...]'da liegt der Fremde, von mir in seinem Bette festgebunden; und, beim Himmel, es ist nicht die schlechteste Tat, die ich in meinem Leben getan!" "
} 
Da mesma forma como nos deixamos seduzir por Toni como uma figura híbrida, entre preto e branco, medo e sedução, infância e idade adulta, vida e morte, uma mulher jovem e forte, mestiça em vários aspectos, $O$ Noivado em São Domingo (Die Verlobung in St. Domingo) nos fascina como feito literário exatamente nos momentos em que as fronteiras do discurso colonialista ficam difusas e deixam de funcionar univocamente. Ao depurar o tema literariamente, Kleist desenvolve uma dinâmica da periferia, da migração e do exílio, que tanto cita o modelo de pensamento eurocêntrico como também o ameaça.

"O prazer do texto" brota quando a dinâmica da migração se reflete em forma de linguagem - quando nos confrontamos com uma retórica da percepção do outro, do afeto, do aleatório e da hibridização, cuja tendência centrifugante se observa até nos detalhes metonímicos. Nesse sentido, a periferia latino-americana não parece ser uma escolha casual ou exótica. Mais do que isso, ela exibe uma situação extrema e adequada para que o autor possa realizar o seu experimento. E apesar disso: não há além-mundo do discurso. Kleist desenvolve a retórica dessa literatura migratória sob a égide do discurso conservador de seu narrador: um discurso, cuja estrutura, apesar de todas as 'minas' literárias, é mantido com esforço até o fim - talvez porque, encantados por um racionalismo eurocêntrico, ocidental, jamais consigamos nos libertar de fato de seu sutil totalitarismo. Porém, a criação de uma literatura periférica, migratória, híbrida por um autor da era de Goethe é o que nos fascina nesse texto enquanto texto literário ou, para usar as palavras de Toni, nos "prende/amarra" (,fesselt"). Precisamos evitar, claro, se é que isso seja possível, 'traduzir' essa literatura precipitadamente para um novo discurso, ainda que seja um bem atual - como o caso do racismo -, e roubarlhe, dessa forma, a sua força subversiva.

\section{Referências bibliográficas}

ANGRESS, Ruth K. "Kleist's Treatment of Imperialism: Die Hermannsschlacht and Die Verlobung in St. Domingo. In: Monatshefte 69/ 1977, 17-33.

BAY, Hansjörg. "'Als die Schwarzen die Weißen ermordeten'. Nachbeben einer Erschütterung des europäischen Diskurses in Kleists 'Verlobung in St. Domingo"'. In: Kleist-Jahrbuch 1998, 80-109. 
BEIL, Ulrich Johannes. “'Kenosis' der idealistischen Ästhetik. Kleists 'Über das Marionettentheater' als Schiller-réécriture". In: Kleist-Jahrbuch 2006, 7599.

BHABHA, Homi. The Location of Culture. New York/London, Routledge, 1994.

BLACKBURN, Robin. The Overthrow of Colonial Slavery 1776-1848. London/New York, 1988.

Buch, Hans Christoph. Die Scheidung von San Domingo. Wie die Negersklaven von Haiti Robespierre beim Wort nahmen. Berlin, 1976.

Campos de Paiva Castro, Rodrigo. Michael Koblhaas - a vitória da derrota. Uma interpretação da novela "Michael Koblhaas", de Heinrich von Kleist. São Paulo [Dissertação de Mestrado em Literatura Alemã], 2006.

De Man, Paul. Allegories of Reading. Yale 1979.

FICK, Carolyn. Para uma (re)definição de liberdade: a Revolução no Haiti e os paradigmas da Liberdade e Igualdade. In: Estudos Afro-Asiáticos 2/ 2004, 355380.

Fineman, Joel. "The History of the Anecdote: Fiction and Fiction". In: H. Aram Veeser (org.): The New Historicism. New York/London, Routledge, 1989, 49-76.

FISCHER, Bernd. "Zur politischen Dimension der Ethik in Heinrich von Kleists Die Verlobung in St. Domingo". In: Dirk Grathoff (org.): Heinrich von Kleist. Studien zu Werk. und Wirkung. Opladen, 1988, 248-262.

GILman, Sander L. "The Aesthetics of Blackness in Heinrich von Kleist's 'Die Verlobung in St. Domingo'”. In: Modern Language Notes 90/ 1975, 661672 .

GoETHE, Johann Wolfgang von. Maximen und Reflexionen (org. Hecker). Weimar, 1907.

GREINER, Bernhard. Kleists Dramen und Erzäblungen. Experimente zum 'Fall' der Kunst. Tübingen/Basel, UTB 2000.

GribNITZ, Barbara. Scbwarzes Mädchen, weißer Fremder. Studien zur Konstruktion von 'Rasse' und Geschlecbt in Heinrich von Kleists Erzählung Die Verlobung in St. Domingo. Würzburg, Königshausen \& Neumann, 2002.

Haverkamp, Anselm. "Schwarz/Weiß. Othello und 'Die Verlobung in St. Domingo"'. In: Weimarer Beiträge 41/ 1995, H.3, 397-409. 
HeCKNER, Elke. "Zur Ambivalenz kolonialer Mimikry in Kleists 'Verlobung in St. Domingo"'. In: Kleist-Jabrbuch 2001, 226-245.

Herrmann, Hans Peter. "Die Verlobung in St. Domingo." In: Walter Hinderer (org.): Kleists Erzählungen. Stuttgart, Reclam, 1998, 111-141.

HoRn, Peter. "Hatte Kleist Rassenvorurteile? Eine kritische Auseinandersetzung mit der Literatur zur Verlobung in St. Domingo". In: Peter Horn: Heinrich von Kleists Erä̈hlungen. Eine Einfübrung. Königstein/Ts. 1978, 134-144.

James, C. L. R. The Black Jacobins. Toussaint l'Ouverture and the San Domingo Revolution. New York, 1989.

KLEIST, Heinrich von. Werke in einem Band. Org.: Helmut Sembdner. München, Hanser, 1990 [5. edição].

KLEIST, Heinrich von. Brandenburger Kleist-Ausgabe (BKA). Org.: Roland Reuß, Peter Staengle, Ingeborg Harms. Basel-Frankfurt/M, 1988 sg., Stroemfeld/Roter Stern, Vol. II 4.

KLEIST, Heinrich von. A marquesa d'O... e outras estórias. Trad. Claudia Cavalcanti. Rio de Janeiro, 1992.

LuBKOLL, Christine. "Soziale Experimente und ästhetische Ordnung. Kleists Literaturkonzept im Spannungsfeld zwischen Klassizismus und Romantik. Die Verlobung in St. Domingo." In: Christine Lubkoll / Günter Oesterle (org.): Gewagte Experimente und kühne Konstellationen. Kleists Werk zwischen Klassizismus und Romantik. Würzburg, 2001 (Stiftung für Romantikforschung, Bd.12), 119-136.

Neumann, Gerhard. "Die Verlobung in St. Domingo. Zum Problem literarischer Mimesis im Werk Heinrich von Kleists". In: Christine Lubkoll / Günter Oesterle (org.): Gewagte Experimente und kühne Konstellationen. Kleists Werk zwischen Klassizismus und Romantik. Würzburg, 2001 (Stiftung für Romantikforschung, Bd.12), 93-117.

NeumanN, Gerhard. "Anekdote und Novelle: Zum Problem literarischer Mimesis im Werk Heinrich von Kleists." In: Inka Kording / Anton Philipp Knittel (org.): Heinrich von Kleist. Neue Wege der Forschung. Darmstadt, Wissenschaftliche Buchgesellschaft, 2003, 177-202.

REUß, Roland. “'Die Verlobung in St. Domingo' - eine Einführung in Kleists Erzählen". In: Inka Kording / Anton Philipp Knittel (org.): Heinrich von 
Beil, U. J. - A subversão da História pela Literatura: O Noivado em São Domingos

Kleist. Neue Wege der Forschung. Darmstadt, Wissenschaftliche Buchgesellschaft, 2003, 71-88.

Rosenfeld, Anatol. História da Literatura e do Teatro Alemães. São Paulo, Edusp, 1993.

SCHERPE, Klaus: "Die First-Contact-Szene. Kulturelle Praktiken bei der Begegnung mit dem Fremden”. In: Weimarer Beiträge 44/ 1998, H. 1, 5473.

SCHMIDT, Jochen. Heinrich von Kleist. Die Dramen und Eræä̈hlungen in ibrer Epoche.

Darmstadt, Wissenschaftliche Buchgesellschaft, 2003.

UerLINGS, Herbert. "Preussen in Haiti? Zur interkulturellen Begegnung in Kleists 'Verlobung in St. Domingo'”. In: Kleist-Jabrbuch, 1991, 185-202.

UerLINGS, Herbert: Poetiken der Interkulturalität. Haiti bei Kleist, Seghers, Müller, Buch und Fichte. Tübingen, 1997.

WeIGEL, Sigrid. "Der Körper am Kreuzungspunkt von Liebesgeschichte und Rassendiskurs in Heinrich von Kleists Erzählung 'Die Verlobung in St. Domingo"'. In: Kleist-Jabrbuch, 1991, 202-218.

Zantop, Susanne. "Verlobung, Hochzeit und Scheidung in St. Domingo. Die Haitianische Revolution in zeitgenössischer deutscher Literatur (17921817)". Em: Sigrid Bauschinger / Susan Cocalis (org.): "Neue Welt" / "Dritte Welt". Interkulturelle Beziehungen Deutschlands zu Lateinamerika und der Karibik. Tübingen/Basel, 1994, 29-52. 